\title{
Factorial experimentation on photodegradation of historical paper by polychromatic visible radiation
}

\author{
Yun Liu ${ }^{1 *} \mathbb{D}$, Tom Fearn² and Matija Strlič ${ }^{1,3}$
}

\begin{abstract}
Quantification of the degradation behaviour of heritage objects is essential to manage the rate of degradation and hence optimise their lifetime. In this research, a $2^{3}$ full factorial experiment was carried out to deepen the understanding of the photodegradation of historical rag paper induced by continuous polychromatic visible radiation. Oxygen concentration, relative humidity and illuminance were investigated as the three environmental factors of primary concern. The effects of these factors on the rate constant of change in diffuse reflectance and tristimulus discolouration were investigated by analysis of variance and multiple linear regression. The three main effects were found to contribute the most to the rate of photodegradation of historical paper, among which relative humidity played the most important role whereas illuminance played the least. This observation is likely to hold when extrapolating the experimental conditions to real conditions in collection storage and display.
\end{abstract}

Keywords: Factorial experimentation, UV/VIS/NIR spectroscopy, Photo-oxidation, Discolouration, Historical paper

\section{Introduction}

The degradation of paper received major attention in photochemistry in the mid twentieth century. Kinetics of the photochemical reactions were mainly investigated using laboratory cellulose exposed to ultraviolet (UV) radiation. It was found that UV wavelengths play a decisive role in determining the reaction kinetics [1-4]. Far and middle monochromatic UV $(\lambda<300 \mathrm{~nm})$ initiates direct photolysis whereas near UV $(\lambda=388 \mathrm{~nm})$ mainly leads to photo-oxidation, which can be explained by the fact that the photons in far and middle UV carry sufficient energy ( $95 \mathrm{kcal} \cdot \mathrm{mol}^{-1}$ at $300 \mathrm{~nm}$ ) for the scission of $\mathrm{C}-\mathrm{C}$ and $\mathrm{C}-\mathrm{O}$ bonds $\left(80-90 \mathrm{kcal} \cdot \mathrm{mol}^{-1}\right)$ [5]. For both mechanisms, the effects of various external and internal factors, such as temperature, oxygen, moisture, the presence of photosensitisers and material composition were

\footnotetext{
*Correspondence: LiuY@si.edu

${ }^{1}$ Museum Support Center, Museum Conservation Institute, Smithsonian Institution, 4210 Silver Hill Rd, Suitland, MD 20746, USA

Full list of author information is available at the end of the article
}

investigated [2, 6-12]. It was observed that under far UV, oxygen played little role whereas moisture strongly inhibited the degradation of cellulose, indicated by reflectance, viscometric degree of polymerization (DP) and alpha cellulose content [13]. However, when exposed to near or polychromatic UV, both oxygen and moisture promoted the rate of degradation as indicated by a decrease in DP and an increase in gaseous degradation products $[3,4]$.

Since UV is excluded from storage and display spaces and polychromatic visible radiation is commonly used for exhibitions in museums and galleries $[14,15]$, the results of UV-induced degradation of paper is not readily applicable to the preservation of historical paper. Although the significance of the photodegradation of paper induced by visible radiation has been acknowledged [16], the results are still very limited in photochemistry. Given that photons in the visible range carry less energy than is required for the photolysis of most chemical bonds in cellulose [5], it is reasonable to assume that photo-oxidation is the main mechanism of the reactions taking place in historical rag paper under exposure to visible radiation. In
Springer Open

(c) The Author(s) 2021. Open Access This article is licensed under a Creative Commons Attribution 4.0 International License, which permits use, sharing, adaptation, distribution and reproduction in any medium or format, as long as you give appropriate credit to the original author(s) and the source, provide a link to the Creative Commons licence, and indicate if changes were made. The images or other third party material in this article are included in the article's Creative Commons licence, unless indicated otherwise in a credit line to the material. If material is not included in the article's Creative Commons licence and your intended use is not permitted by statutory regulation or exceeds the permitted use, you will need to obtain permission directly from the copyright holder. To view a copy of this licence, visit http://creativecommons.org/licenses/by/4.0/. The Creative Commons Public Domain Dedication waiver (http://creativeco mmons.org/publicdomain/zero/1.0/) applies to the data made available in this article, unless otherwise stated in a credit line to the data. 
this case, as suggested by research using near UV $[3,4]$, environmental factors, such as oxygen and moisture are expected to play important roles in the photodegradation processes.

Quantifying the effects of the environmental factors on the photodegradation processes of historical paper can provide essential evidence for collection management. But the experimental design and data interpretation can be challenging when multiple factors are involved. Factorial experimentation provides an efficient way to examine not only the main effects-the effects of each single independent factor, but also the interactions between the factors, on measurable responses of the materials with an optimised number of experimental runs [17]. A full factorial experimental design is the method of choice when the number of factors is small. In such a design, multiple factors are involved, each taking possible values at different levels and the experimental runs taking on all possible combinations of these levels across all the factors [18]. As a result, the main effects and interaction effects are quantified and a model that describes the effects of statistical significance can be established.

In this paper, we discuss the use of a $2^{3}$ full factorial experiment to investigate the effects of atmospheric oxygen concentration $\left(\left[\mathrm{O}_{2}\right]\right)$, relative humidity $(\mathrm{RH})$ and illuminance $\left(E_{v}\right)$ of visible radiation on the photodegradation of historical rag paper. We deliberately used sacrificial historical rag papers of various material compositions as samples, to represent the complex material systems as a result of natural ageing [19]. Diffuse reflectance in the visible and near-infrared range was monitored through the experimental runs as a primary indicator of the photodegradation. Given that discolouration is a major concern for paper preservation, tristimulus total colour change expressed as CIE $\Delta \mathrm{E}_{00}$ was calculated as a secondary response variable to construct a model that provides direct evidence for collection management [20-22].

\section{Experimental}

\section{Samples and experimental setup}

Twenty-three sacrificial historical samples of rag paper (eighteenth-twentieth century) were collected for the experiment, covering a wide range of variations in composition which was assessed visually. The average thickness of samples ranged from 0.101 to $0.190 \mathrm{~mm}$ with the average being $0.136 \mathrm{~mm}$. Each sample was divided into eight $1.0 \times 1.5 \mathrm{~cm}$ rectangles, each of them for one factorial experiment. It was ensured that stains and exceptionally degraded areas were avoided for minimal variations between the subsamples in their initial state.

The experimental setup is illustrated in Fig. 1. For each experiment, 23 subsamples were attached to a ring of Whatman filter paper No. 1 and held by sample

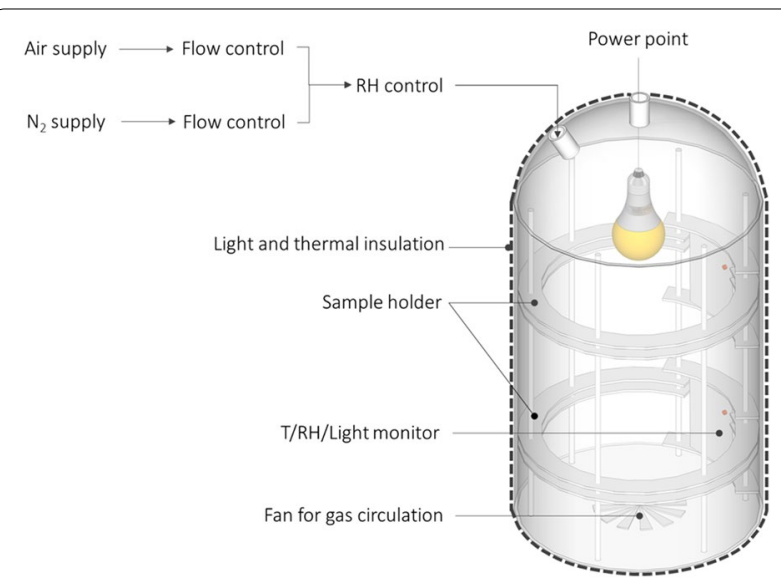

Fig. 1 Diagram showing the setup of the reaction chamber for the accelerated photodegradation experimental runs

holders in the ageing chamber. An LED light bulb (240 V, $13 \mathrm{~W}, 1521 \mathrm{~lm}$, Philips, Netherlands) was used for each experiment. $\left[\mathrm{O}_{2}\right](\mathrm{v} / \mathrm{v} \%)$ was regulated by Aalborg GFC aluminum body mass flow controller (Caché Instrumentation, UK). V-GenTM Dew Point/RH Generator (InstruQuest Inc., US) was used to regulate the RH in the chamber. The desired atmospheres were continuously circulated at $200 \mathrm{ml} \cdot \mathrm{min}^{-1}$ through the systems $24 \mathrm{~h}$ before and during the irradiation. The temperature was kept at $21{ }^{\circ} \mathrm{C}$ to limit as much as possible the interference of thermal degradation during the experiment. The environmental conditions inside the chamber were monitored using HOBO Data Loggers (U12-012, Tempcon Instrumentation, UK). The spectral power distribution (SPD) of the light source at the positions of the samples during the degradation experiment was measured using GL SPECTIS 1.0 spectrometer (GL Optic, Poland).

\section{Factorial experimentation}

A $2^{3}$ full factorial experiment was carried out to investigate the effect of $\left[\mathrm{O}_{2}\right](\mathrm{v} / \mathrm{v} \%), \mathrm{RH}(\mathrm{p} / \mathrm{p} \%)$ and illuminance $\left(E_{v}, l x\right)$ on the photodegradation kinetics of historical paper samples. Table 1 summarises the settings of the two levels for each factor (Table 1a) and the combination of the three factors for each experimental run (Table 1b). To achieve the time and resource efficiency, complete randomization of the experimental runs was compromised by carrying out two runs required for the same $\left[\mathrm{O}_{2}\right]$ and $\mathrm{RH}$ levels but different $E_{v}$ levels at the same time. This was carried out by positioning two sets of samples at different levels where the desired $E_{v}$ was obtained in the reaction chamber. Due to time and resource constraints, not all experimental runs were carried out for the same length of time. The duration of degradation ranges from 12 to 
Table 1 Specifications of the experiment

(a) The two levels of the three factors: $\left[\mathrm{O}_{2}\right], \mathrm{RH}$, and illuminance used in the $2^{3}$ factorial design of experiments ${ }^{\mathrm{a}}$

\begin{tabular}{lcr}
\hline & Low $(-\mathbf{1})$ & High (1) \\
\hline $\left.\mathrm{O}_{2}\right](\%)$ & 0 & 21 \\
$\mathrm{RH}(\%)$ & $20(0.49)$ & $70(1.71)$ \\
$\mathrm{E}_{\mathrm{v}}$ & $5000 \mathrm{~lx}$ & $20,000 \mathrm{Ix}$ \\
\hline
\end{tabular}

(b) The combinations of conditions used for each experiment in the factorial experiments ${ }^{\text {b }}$

\begin{tabular}{llll}
\hline Experimental run number & {$\left[\mathbf{O}_{2}\right]$} & RH & $\mathbf{E}_{\mathrm{v}}$ \\
\hline 2 & -1 & -1 & -1 \\
1 & +1 & -1 & -1 \\
3 & -1 & +1 & -1 \\
4 & +1 & -1 & -1 \\
2 & -1 & -1 & +1 \\
1 & +1 & +1 & +1 \\
3 & -1 & +1 & +1 \\
4 & +1 & & +1 \\
\hline
\end{tabular}

${ }^{a}$ The volumetric water vapor concentration for each condition set is presented in parentheses in the 3rd row

b -1 and +1 refer to the low and high conditions respectively specified in Table 2(a)

31 days and at least 9 measurements were carried out for each experimental run.

\section{Reflectance spectroscopy}

Diffuse reflectance $(\mathrm{R})$ was measured using a custom hyperspectral imaging system manufactured by Camlin (Lisburn, UK). The system was equipped with individual components, including a VNIR camera (spectral range: 400-1000 nm, spectral resolution: $2 \mathrm{~nm}$ ) coupled with XENOPLAN 2.8/500902 lens (Schneider-KREVZNACH, Germany) and halogen light sources (manufacturer unknown). Dark calibration was carried out with the lens capped and white calibration was carried out using a Florilon $^{\mathrm{TM}}$ Standard (EFWS-99-02c, Avian Technologies LLC, US). Scanning speed $\left(0.8 \mathrm{~mm} \cdot \mathrm{s}^{-1}\right)$ was determined in relation to the exposure time $(50 \mathrm{~ms})$ and the aperture size (f/5.6) of the camera to obtain square pixels. During one scan, the samples were exposed to $254.4 \mathrm{~lx} \cdot \mathrm{h}$ at $25 \pm 2{ }^{\circ} \mathrm{C}$ and $23 \pm 2 \% \mathrm{RH}$, which is less than $0.3 \%$ of light exposure they received during each interval of the experimental runs. Therefore, the degradation caused by data collection was considered insignificant. For each experimental run, measurements were taken at intervals of 0.09-5 days to ensure a balance between minimal disturbance to the reactions, measurable change of the samples, and resource constraints. The spatial resolution of the images was 625 ppi.

\section{Calibration}

The wavelength calibration of the hyperspectral VNIR camera was carried out using Spectralon ${ }^{\circledR}$ Calibrated
Multi-Component Wavelength Calibration Standard (WCS-MC-010, Labsphere, US). Given that the repeatability of the hyperspectral imaging measurements can be affected by the instability of the hyperspectral imaging system as well as the samples, 14 measurements of one piece of reference sample were taken over 32 days. Average diffuse reflectance was calculated for each image and relative standard deviation was calculated as the standard deviation divided by the mean of diffuse reflectance for the 14 images (Additional file 1: Figure S1). Good consistency for pixels of paper was observed, where the RSD of variation is generally below $1 \%$. This assessment provides important information for the evaluation of the statistical significance of the measured change in diffuse reflectance for the accelerated degradation experiment.

\section{Data processing}

The diffuse reflectance was averaged over all the pixels of each hyperspectral image of the historical paper samples. A data cube of change in diffuse reflectance was constructed for each experimental condition where the horizontal axis represents the wavelength $(\lambda)$ of interest (424-853 nm), the vertical axis represents the sample numbers, and the depth axis represents the time (day) that was taken in the degradation experiment. $\Delta R$ across the full range of wavelength was calculated for each sample by subtracting the reflectance spectrum before degradation from the reflectance spectrum at each time interval. The spectra of $\Delta \mathrm{R}$ were then treated using Savitzky-Golay filtering (2nd order polynomial, frame length 19) [23]. Subsequently, by averaging the 
reflectance across all the samples for each experimental condition, data cubes of mean reflectance $(\Delta R)$ were constructed, where the first dimension represents the experimental conditions, the second dimension represents $\lambda$, and the third dimension represents the degradation time.

The visible range of the spectra $(424-780 \mathrm{~nm})$ was used to calculate tristimulus colourimetric values. CIE L"a*b* values were calculated based on CIE Standard Illuminant D50 and CIE 1964 colour matching function for $10^{\circ}$ observers $[24,25]$. Calibration was established using an X-Rite colourchecker (X-Rite, US) and applied to the calculated CIE L*a*b* of each paper sample of historical paper. Subsequently, $\Delta \mathrm{E}_{00}$ was calculated for each sample at each time interval $[20,21,26]$. A data cube of $\Delta \mathrm{E}_{00}$ was constructed where the horizontal axis represents the time of exposure, the vertical axis represents the samples, and the depth axis represents different experimental runs. All the data processing and analyses were carried out in Matlab R2017a.

\section{Results and discussion}

Nine slices were selected at $\lambda$ of $\sim 50 \mathrm{~nm}$ intervals from the data cube of $\Delta R$. The progress of $\Delta R$ over time under different experimental conditions is presented in Fig. 2. No induction time was observed for the photodegradation of the samples. Most change took place in the first 10 days upon exposure to the environments and the total change did not exceed $10 \%$ of the reflectance at the corresponding $\lambda . \Delta R$ decreased as $\lambda$ increased. The change led to shifts of the reflectance spectra to the blue end, leading to visual bleaching. This blueshift has been observed by other researchers [27] and it corresponds to the photooxidation behaviour of cellulose under exposure to near $\mathrm{UV}$ radiation, where decreasing $\Delta \mathrm{R}$ was observed as $\lambda$ increased from 350 to $500 \mathrm{~nm}$ [3]. This suggests that the photo-oxidation is likely to be the main mechanism of the degradation of historical rag paper upon exposure to visible radiation, where chromophores formed during ageing are broken by radicals such as superoxide and peroxide [28-30].

According to the Hurter-Driffield curve of sensitometry, density-the number of reactive particles multiplied by the coefficient of absorption, is logarithmically dependent on time of exposure [31]. This logarithmic dependence of change on time of exposure has been observed in the photochemical reactions of a number of materials, including photographic plates [31], polyester resins [32] and organic coatings [33]. Based on these studies, it is plausible to approximate the dependence of $\Delta \mathrm{R}$ on time, as shown in Fig. 2, using a logarithmic function ${ }^{1}$ :

$$
\Delta=\mathrm{A}_{0}+\mathrm{k}_{\Delta} \cdot \ln (\mathrm{t}), \mathrm{t} \geq 0.09
$$

where $\Delta$ represents $\Delta \mathrm{R}, \mathrm{A}_{0}$ and $\mathrm{k}_{\Delta}$ are the regression coefficients, and $t$ is the time of degradation in day. This logarithmic relationship between $\Delta$ and $t$ implies a fast initial change in discolouration of historical paper. $\mathrm{A}_{0}$ represents the $\Delta R$ that takes place in the space of one day. Based on Eq. 1, the rate of the progress of $\Delta R\left(K_{\Delta R}\right)$ was obtained as a function of $\mathrm{t}$ :

$$
\mathrm{K}_{\Delta}=\mathrm{d} \Delta / \mathrm{dt}=\mathrm{k}_{\Delta} \cdot \mathrm{t}^{-1}, \mathrm{t} \geq 0.09
$$

where $\mathrm{K}_{\Delta}$ represents $\mathrm{K}_{\Delta \mathrm{R}}$, $\mathrm{t}$ is the time of degradation in day, and $k_{\Delta}$ represents the rate constant.

Based on Eqs. 1, 2, $\mathrm{k}_{\Delta \mathrm{R}}$ was estimated across the selected $\lambda s$ for all the experimental runs (Additional file 1: Table S1). The relationship between $k_{\Delta R}$ and $\lambda$ for different environmental conditions is presented in Fig. 3. Similar to the observations made on $\Delta \mathrm{R}, \mathrm{k}_{\Delta \mathrm{R}}$ decreased as $\lambda$ increases for each experimental condition. This trend of $k_{\Delta R}$ can be described as a function of $\lambda$ across 424-853 $\mathrm{nm}$ using 2nd order polynomial approximations $\left(\mathrm{R}^{2} \geq 0.99\right)$ (Additional file 1: Table S2a) or a function of $\lambda<601 \mathrm{~nm}$ using a linear approximation $\left(\mathrm{R}^{2} \geq 0.96\right)$ (Additional file 1: Table S2b). Furthermore, Fig. 3 shows that the samples degraded by all factors at high levels showed the largest $k_{\Delta R}$, whereas the samples degraded by all factors at low levels showed the smallest $k_{\Delta \mathrm{R}}$. This implies that $\mathrm{k}_{\Delta \mathrm{R}}$ is likely to be positively correlated with either $\left[\mathrm{O}_{2}\right], \mathrm{RH}, \mathrm{E}_{\mathrm{v}}$, or their combinations. These observations are in strong contrast with the results obtained for cellulose using far UV, but are in agreement with the results obtained at $388 \mathrm{~nm}$ and heterogeneous UV [3]. It again provides evidence to support the similarity in degradation mechanism between irradiation with near/heterogeneous UV radiation and visible radiation.

Prior to carrying out analysis of variance (ANOVA) to analyse the significance of the effects of of $\left[\mathrm{O}_{2}\right], \mathrm{RH}$, $E_{v}$, and their interactions on $k_{\Delta R}$, the significance of the two-factor and three-factor interactions was examined using a half-normal probability plot. This type of plot is often used to assess the statistical significance of effects in a factorial experiment without replications [34]. In the half-normal plot for $\mathrm{k}_{\Delta \mathrm{R}-444}$ (Fig. $4 \mathrm{a}$ ), a clear break between main effects and interactions can be observed.

\footnotetext{
${ }^{1}$ It should be noted that the logarithmic approximation only provides one possible interpretation of the data. The upper end of the data can also be approximated using a linear function. Since there is insufficient information in the available data to decide explicitly between the interpretations, the question remains open until further research is carried out and more insights into the discolouration processes are gained.
} 



Fig. 2 Scatter plots showing the progression of $\triangle \mathrm{R}$ over time during the accelerated degradation under eight experimental conditions: a $0 \%\left[\mathrm{O}_{2}\right]$, $70 \% \mathrm{RH}$ and 20,000 |x; b 0\% $\left[\mathrm{O}_{2}\right], 70 \% \mathrm{RH}, 5000 \mathrm{~lx} ; \mathbf{c} 21 \%\left[\mathrm{O}_{2}\right], 70 \% \mathrm{RH}, 20,000 \mathrm{~lx} ; \mathbf{d} 21 \%\left[\mathrm{O}_{2}\right], 70 \% \mathrm{RH}, 5000 \mathrm{~lx} ; \mathbf{e} 0 \%\left[\mathrm{O}_{2}\right], 20 \% \mathrm{RH}, 20,000 \mathrm{~lx} ; \mathbf{f} 0 \%\left[\mathrm{O}_{2}\right]$, $20 \% \mathrm{RH}, 5000 \mathrm{~lx} ; \mathbf{g} 21 \%\left[\mathrm{O}_{2}\right], 20 \% \mathrm{RH}, 20,000 \mathrm{~lx}$; and $\mathbf{h} 21 \%\left[\mathrm{O}_{2}\right], 20 \% \mathrm{RH}, 5000 \mathrm{~lx}$. The trends over the entire time span are approximated using a logarithmic relationship 

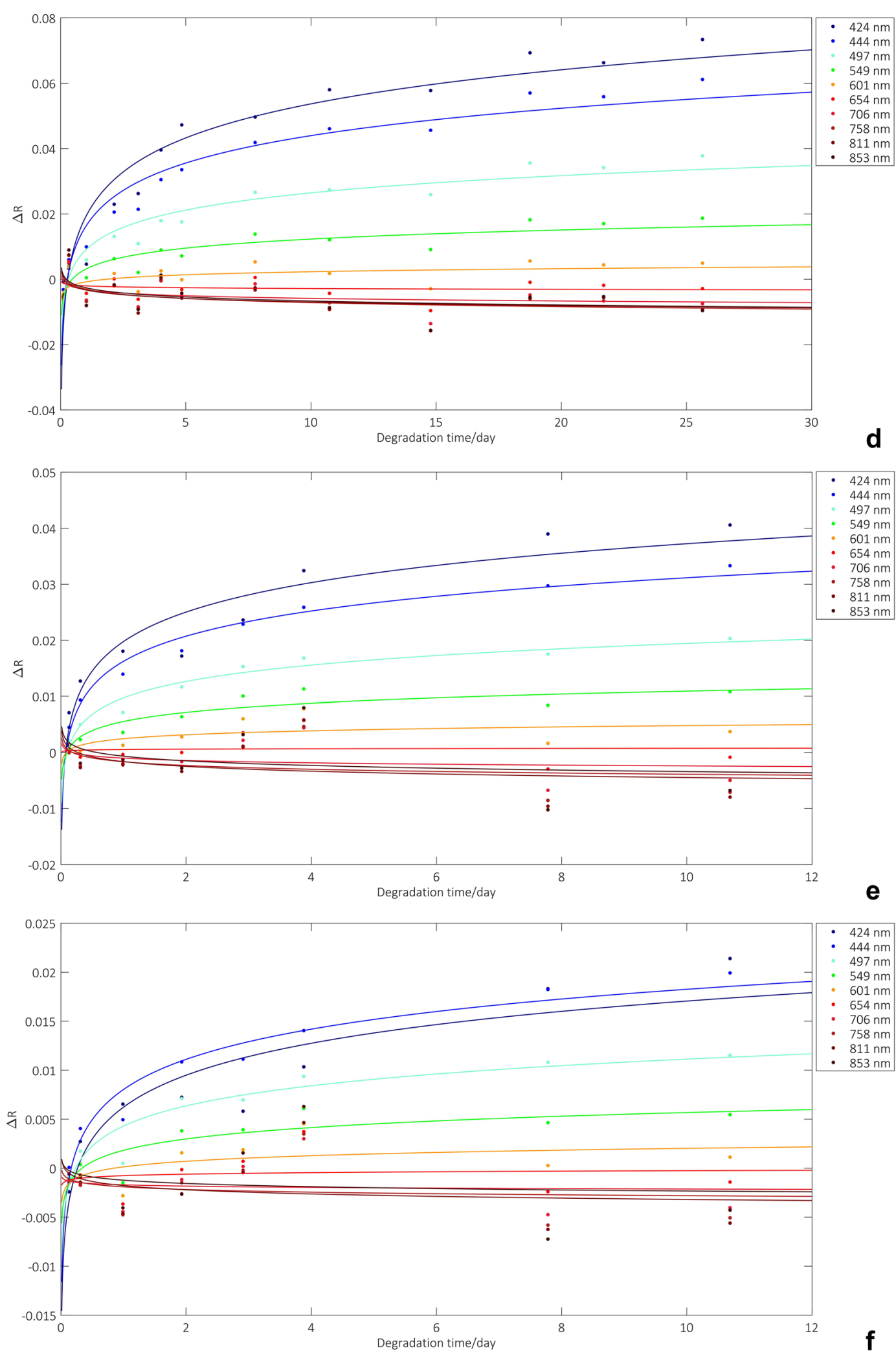

- $424 \mathrm{~nm}$

- $444 \mathrm{~nm}$

- $497 \mathrm{~nm}$

- $549 \mathrm{~nm}$

$601 \mathrm{~nm}$

- $654 \mathrm{~nm}$

- $758 \mathrm{~nm}$

- $811 \mathrm{~nm}$

$853 \mathrm{~nm}$

Fig. 2 continued 

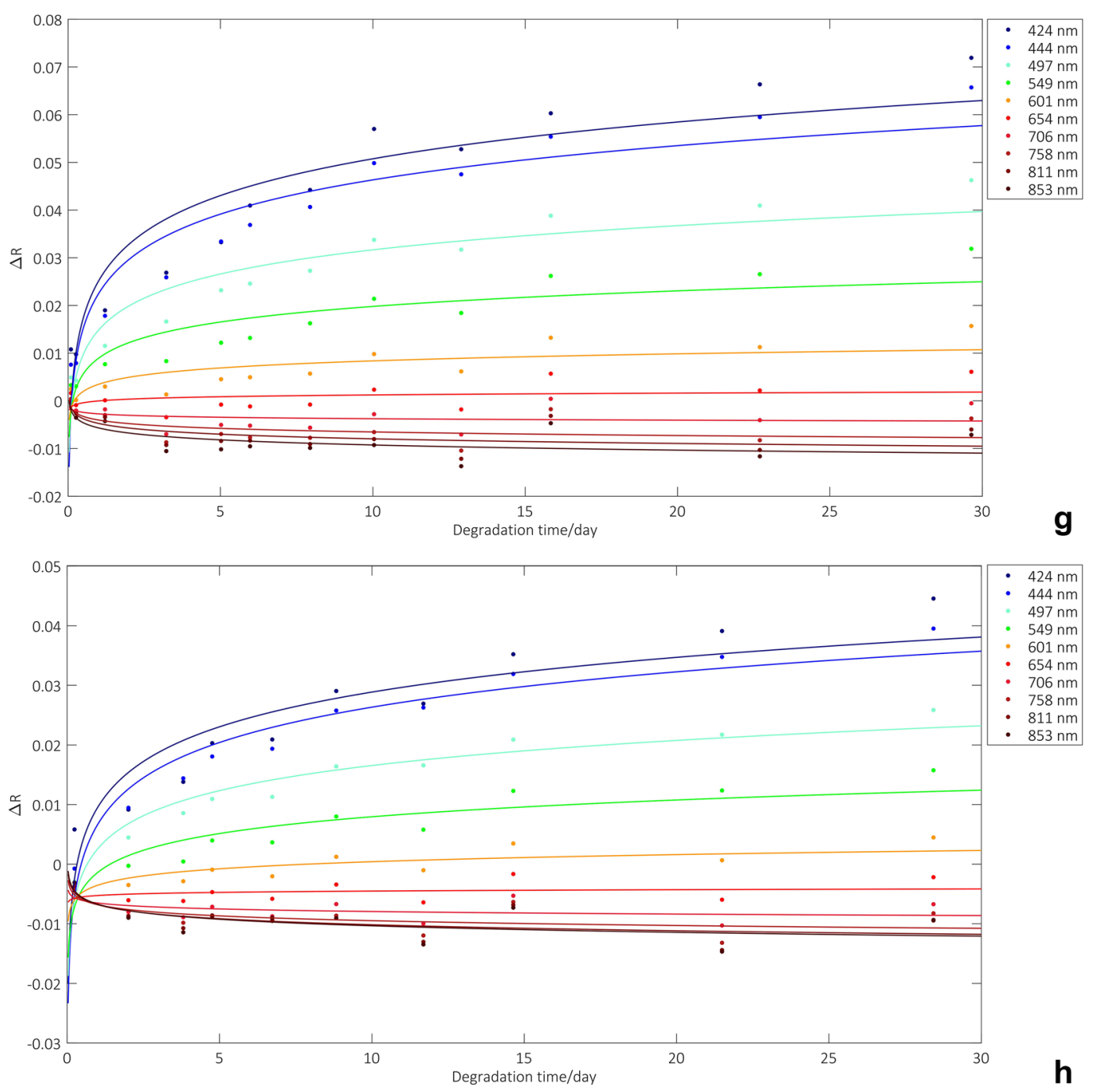

Fig. 2 continued

The data points representing three-factor and two-factor interactions align on a straight line through the origin which defines null effects, whereas the data points representing main effects clearly deviate from this line, indicating that the main effects of $\left[\mathrm{O}_{2}\right], \mathrm{RH}$ and $\mathrm{E}_{\mathrm{v}}$ are much stronger than the interaction effects. This plot provides a reasonable justification to include the two-factor and the three-factor interactions in the error for ANOVA.

Based on the results of the half-normal plot, ANOVA was carried out for $k_{\Delta R}$ at the nine selected values of $\lambda$ based on this model:

$$
y_{i j k}=\mu+\alpha_{i}+\beta_{j}+\gamma_{k}+\varepsilon_{i j k}
$$

where $y_{i j k r}$ represents an observation of $k_{\Delta R}, i, j$, and $k$ represent the levels $i(i=1,2), j(j=1,2)$ and $k(k=1$,
2) of factors $\left[\mathrm{O}_{2}\right], \mathrm{RH}$, and $\mathrm{E}_{\mathrm{v}}$, respectively (Table 1). $\mu$ is the overall mean, $\alpha_{\mathrm{i}}, \beta_{\mathrm{j}}$ and $\gamma_{\mathrm{k}}$ are the deviations of groups of factors $\left[\mathrm{O}_{2}\right], \mathrm{RH}$ and $\mathrm{E}_{\mathrm{v}}$, respectively, from the overall mean $\mu$ due to each corresponding factor. $\varepsilon_{\mathrm{ijk}}$ is the random error.

For $\mathrm{k}_{\Delta \mathrm{R}}$ at $\lambda<549 \mathrm{~nm}$, consistent results of ANOVA were obtained. As an example, Table 2a summarises the results of ANOVA for $k_{\Delta R}$ at $444 \mathrm{~nm}\left(k_{\Delta R-444}\right)$. As expected from the half-normal plot (Fig. 4a), all three main effects were found significant. Among the three, $\mathrm{RH}$ had the strongest effect while $E_{v}$ had the weakest, given the range of each factor investigated in the experiment. Since that the experimental ranges of $\mathrm{RH}$ and $\left[\mathrm{O}_{2}\right]$ are realistic and the range of $\mathrm{E}_{\mathrm{v}}$ is largely exaggerated from the real range recommended for the display in museums 


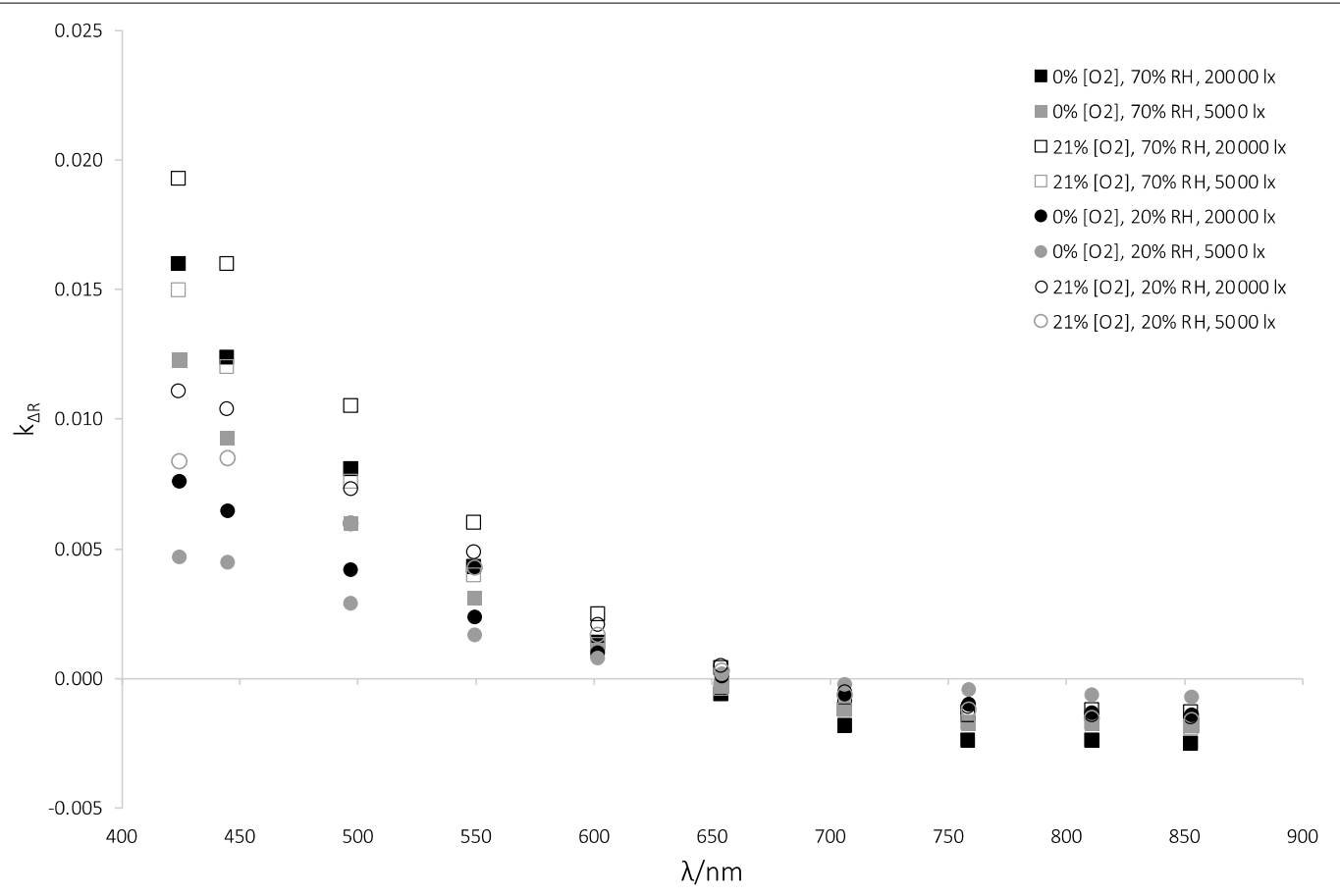

Fig. 3 Plot showing the relationship between $k_{\Delta R}$ and $\lambda$ for historical paper samples under different experimental conditions

(50-200 lx) [35], the effect of $E_{v}$ is likely to be even smaller in a real scenario.

Based on the results of ANOVA and under the assumption that the main effects were linear, regression of $\mathrm{k}_{\Delta \mathrm{R}-444}$ on $\left[\mathrm{O}_{2}\right], \mathrm{RH}$ and $\mathrm{E}_{\mathrm{v}}$ was carried out (Table 3). Since the intercept is likely to be insignificant $(\mathrm{p}>0.05), \mathrm{k}_{\Delta \mathrm{R}-444}$ can be expressed as $\mathrm{k}_{\Delta \mathrm{R}-444}=0.0178 \cdot\left[\mathrm{O}_{2}\right]+0.0099 \cdot \mathrm{RH}$ $+1.83 \times 10^{-7} \cdot \mathrm{E}_{\mathrm{v}}$, where $\left[\mathrm{O}_{2}\right]$ and $\mathrm{RH}$ are in ratio and $\mathrm{E}_{\mathrm{v}}$ is in $1 x$. This function can be used to estimate the contributions of main effects to $k_{\Delta R}$ across 424-601 nm based on the relationship between $\mathrm{k}_{\Delta \mathrm{R}}$ and $\lambda$ (Fig. 3, Additional file 1: Table S2).

The results of ANOVA deviated from the results presented in Table $2 \mathrm{a}$ when $\lambda>601 \mathrm{~nm}$. At $549 \mathrm{~nm}$, although the main effects on $k_{\Delta R}$ were still found stronger than the effects of the interactions, as suggested by the half-normal plot (Fig. $4 \mathrm{~b}$ ), the strength of the effects started to look ambiguous as the data points representing the main effects align on the null-effect line in the half-normal probability plot (Fig. 4b) and the p-values of the effects of $\mathrm{RH}$ and $\mathrm{E}_{\mathrm{v}}$ were found above 0.05 (Table $2 \mathrm{~b}$ ). Completely random results were obtained beyond $601 \mathrm{~nm}$, indicating that the signal to noise ratio of the measurement increased while the effect size reduced for almost all the experimental conditions at $\lambda>549 \mathrm{~nm}$. In fact, $\Delta \mathrm{R}$ dropped to below $1 \%$ of the reflectance measurements beyond $601 \mathrm{~nm}$, which is the same level as the uncertainty of the measurements. This indicates that beyond
$601 \mathrm{~nm}, \mathrm{k}_{\Delta \mathrm{R}}$ was likely to be unmeasurable by the instruments used in this research. Therefore, in this research, it is plausible to conclude that $\mathrm{O}_{2}, \mathrm{RH}$, and continuous polychromatic visible radiation only induced observable change in diffuse reflectance of historical paper below $601 \mathrm{~nm}$.

In collection management, direct assessment of tristimulus total colour change is essential to support decision making. This is because it is used for the condition assessment of objects in practice and it is used to define the damage threshold of objects due to discolouration by professionals [36]. Therefore, in this research, the reflectance was interpreted in CIELAB colour space by calculating tristimulus colourimetric values using the visible range of the reflectance spectra $(424-780 \mathrm{~nm})$. Average total colour change $\left(\Delta \mathrm{E}_{00}\right)[20,21]$ was calculated over the 23 samples for each experimental run and its progress over time is plotted in Fig. 5. Similar to the observations made for $\mathrm{k}_{\Delta \mathrm{R}}$, the samples degraded at high $\left[\mathrm{O}_{2}\right]$, $R H$, and $E_{v}$ underwent the greatest discolouration $\left(\Delta E_{00}\right.$ $>3.0$ ), whereas samples degraded at low $\left[\mathrm{O}_{2}\right], \mathrm{RH}$, and $\mathrm{E}_{\mathrm{v}}$ showed the least $\left(\Delta \mathrm{E}_{00}<1.0\right)$. This suggests that $\mathrm{O}_{2}$, moisture, and visible radiation are all likely to promote the discolouration of historical rag paper. It also suggests that in most cases, the discolouration can be detected by unaided human vision [25, 37-40].

Similar to $\Delta \mathrm{R}, \Delta \mathrm{E}_{00}$ showed logarithmic dependence on time under each experimental condition. Based 


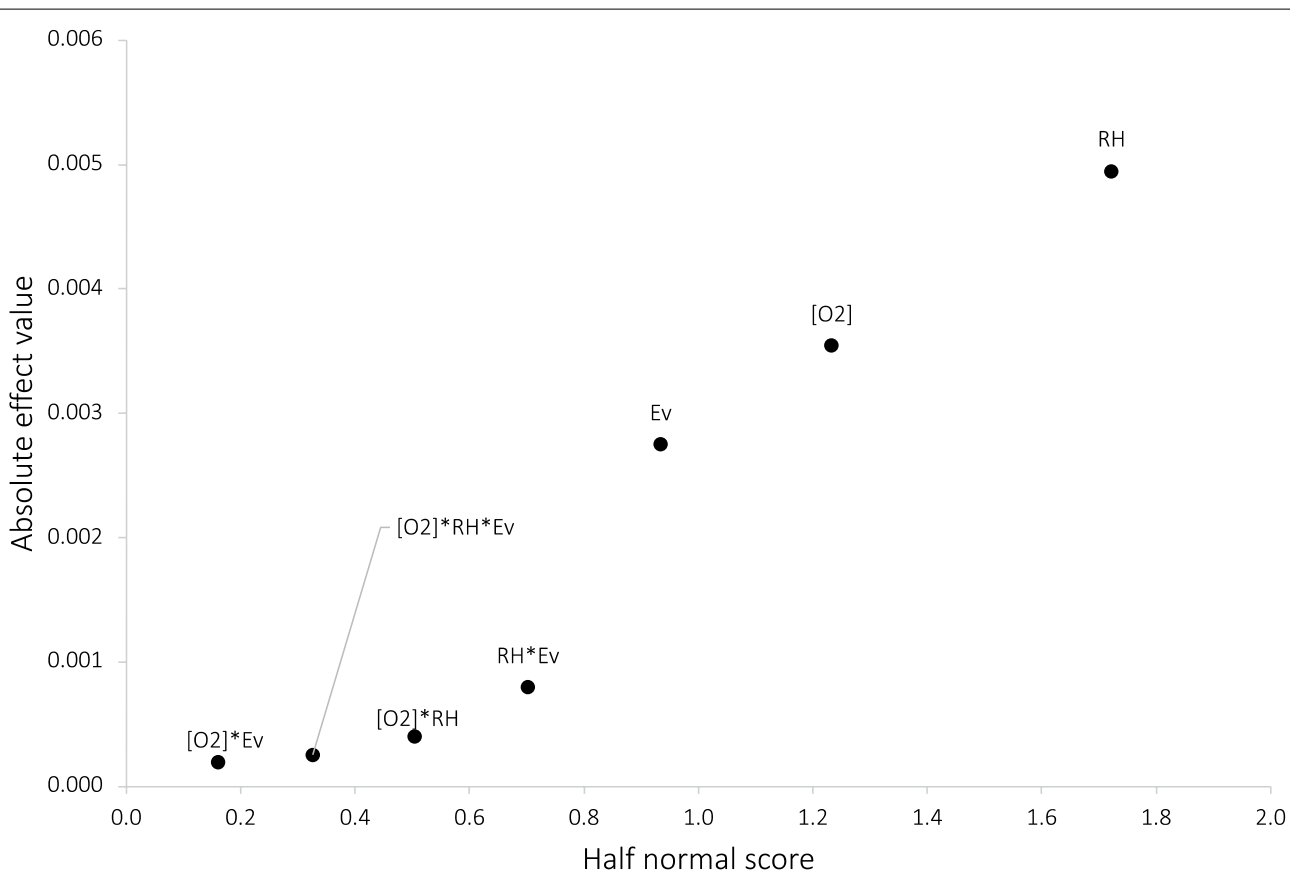

a.

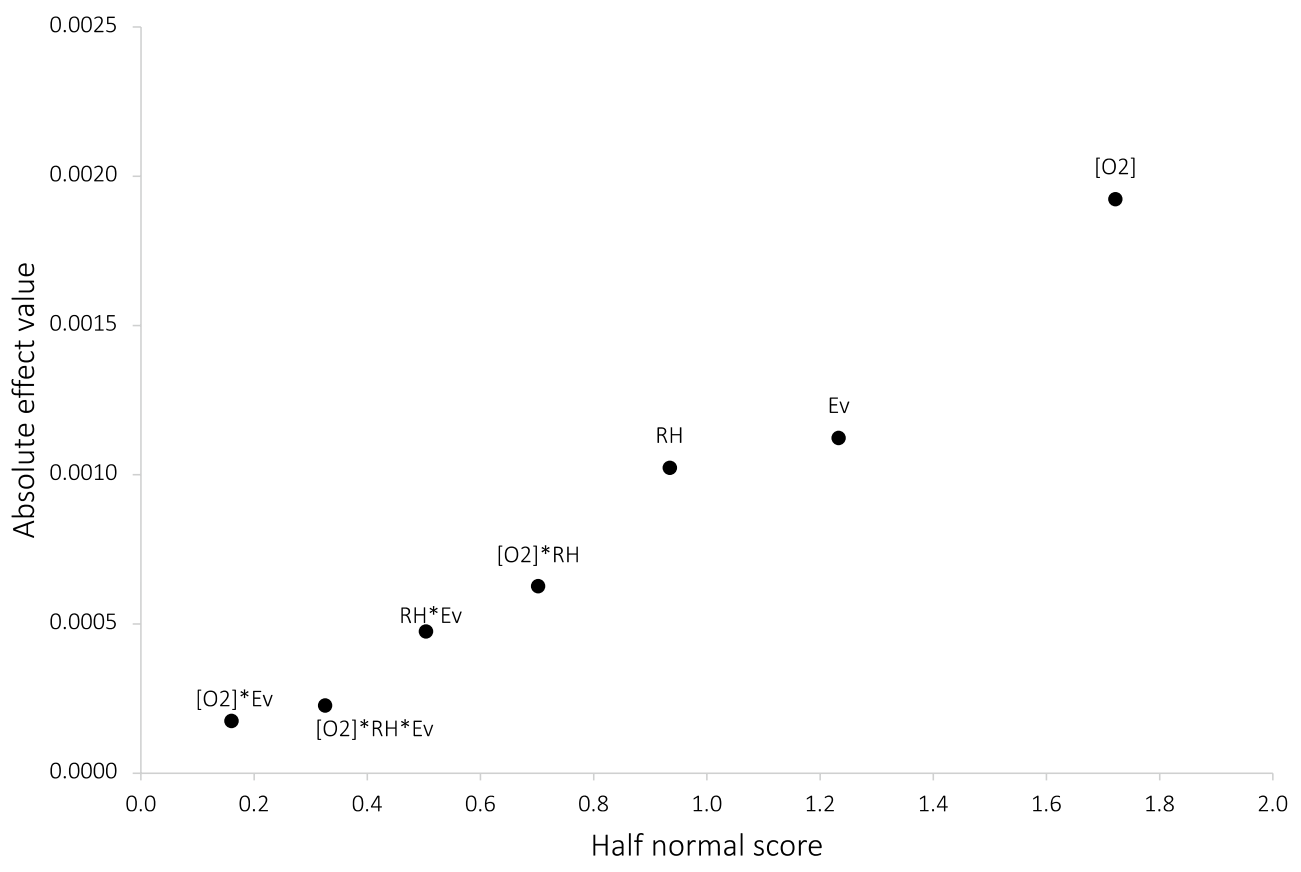

b.

Fig. 4 Half normal probability plots for the effects of $\left[\mathrm{O}_{2}\right], \mathrm{RH}, \mathrm{E}_{\mathrm{v}}$ and their interactions on $\mathbf{a} \mathrm{k}_{\Delta R-444}$ and $\mathbf{b} \mathrm{k}_{\Delta \mathrm{R}-549}$

on Eqs. 1, 2, the rate constant of the progress of $\Delta \mathrm{E}_{00}$ $\left(\mathrm{k}_{\triangle \mathrm{E} 00}\right)$ was obtained (Additional file 1: Table S3) and the relationship between $\mathrm{k}_{\Delta \mathrm{E} 00}$ and $\mathrm{k}_{\Delta \mathrm{R}}$ is explored in Fig. 6. Strong linear correlations were observed across the range of investigated $\lambda$. This linearity suggests that despite the effect of the sensitivity of human vision in tristimulus colourimetry [24], $\Delta \mathrm{E}_{00}$ can be used as an analytical method to provide comparable results to reflectance spectroscopy for the visible radiation induced photodegradation of historical rag paper. It also suggests that the results of ANOVA for $k_{\Delta R}$ can be carried over to $k_{\Delta E 00}$, i.e., the main effects of $\left[\mathrm{O}_{2}\right], \mathrm{RH}$ and $\mathrm{E}_{\mathrm{v}}$ drove the rate of 
Table 2 Summary of ANOVA for the effects of $\left[\mathrm{O}_{2}\right], \mathrm{RH}$, and $\mathrm{E}_{\mathrm{v}}$ on $\mathrm{k}_{\triangle \mathrm{R}-444}$ and $\mathrm{k}_{\triangle \mathrm{R}-549}$

\begin{tabular}{|c|c|c|c|c|c|}
\hline \multicolumn{6}{|c|}{ (a) $k_{\Delta R-444}$} \\
\hline & Sum of squares & DF & Mean square & F value & $p$ value \\
\hline$\left[\mathrm{O}_{2}\right]$ & $2.52 \times 10^{-5}$ & 1 & $2.52 \times 10^{-5}$ & 55.86 & 0.0017 \\
\hline $\mathrm{RH}$ & $4.90 \times 10^{-5}$ & 1 & $4.90 \times 10^{-5}$ & 108.60 & 0.0005 \\
\hline$E_{v}$ & $1.51 \times 10^{-5}$ & 1 & $1.51 \times 10^{-5}$ & 33.52 & 0.0044 \\
\hline Error & $1.80 \times 10^{-6}$ & 4 & $4.50 \times 10^{-7}$ & & \\
\hline \multicolumn{6}{|c|}{ (b) $k_{\Delta R-549}$} \\
\hline & Sum of squares & DF & Mean square & F value & $\mathrm{p}$ value \\
\hline$\left[\mathrm{O}_{2}\right]$ & $7.41 \times 10^{-6}$ & 1 & $7.41 \times 10^{-6}$ & 21.25 & 0.0010 \\
\hline $\mathrm{RH}$ & $2.10 \times 10^{-6}$ & 1 & $2.10 \times 10^{-6}$ & 6.03 & 0.0701 \\
\hline$E_{v}$ & $2.53 \times 10^{-6}$ & 1 & $2.53 \times 10^{-6}$ & 7.26 & 0.0544 \\
\hline Error & $1.40 \times 10^{-6}$ & 4 & $3.49 \times 10^{-7}$ & & \\
\hline
\end{tabular}

DF degree of freedom

Table 3 Summary of the estimated coefficients for the regression analysis of $k_{\triangle R-444}$

\begin{tabular}{lllrl}
\hline Variables & Estimated coefficients & SE & t-stat & p value \\
\hline Intercept & 0.0014 & 0.0007 & 2.1239 & 0.1009 \\
{$\left[\mathrm{O}_{2}\right]$} & 0.0178 & 0.0024 & 7.4737 & 0.0017 \\
$\mathrm{RH}$ & 0.0099 & 0.0010 & 10.4210 & 0.0005 \\
$\mathrm{E}_{\mathrm{v}}$ & $1.8300 \times 10^{-7}$ & $3.1700 \times 10^{-8}$ & 5.7895 & 0.0044 \\
\hline
\end{tabular}

SE represents the standard error of the estimated coefficients, $t$-stat and $p$ value indicate the significance of the estimated coefficients, RMSE represents the root mean square error of the fitted models, and $\mathrm{R}^{2}$ indicates the goodness-of-fit of the fitted models

Number of observations: 8 , error degrees of freedom: 4, RMSE: $0.0007, \mathrm{R}^{2}=$ $0.98, p$ value $=0.0007$

discolouration of historical rag paper. Therefore, under the assumption that the main effects are linear through the ranges of the factors, $\mathrm{k}_{\Delta \mathrm{E} 00}$ can be described as a function of $\left[\mathrm{O}_{2}\right], \mathrm{RH}$ and $\mathrm{E}_{\mathrm{v}}$ by regression analysis $\left(\mathrm{k}_{\triangle \mathrm{E} 00}\right.$ $\left.=0.69 \cdot\left[\mathrm{O}_{2}\right]+0.41 \cdot \mathrm{RH}+8.38 \times 10^{-6} \cdot \mathrm{E}_{\mathrm{v}}, \mathrm{R}^{2}=0.97\right)$ (Additional file 1: Table S4). High $\mathrm{R}^{2}$ values indicate sufficient fit of the model to describe $\mathrm{k}_{\triangle \mathrm{E} 00}$. Positive coefficients indicate that the effects of $\left[\mathrm{O}_{2}\right], \mathrm{RH}$, and $\mathrm{E}_{\mathrm{v}}$ are all positive on $\mathrm{k}_{\triangle \mathrm{E} 00}$.

To obtain the model for $\Delta \mathrm{E}_{00}$, further ANOVA and regression analysis were carried out to determine the explanatory variables and their regression coefficients for $\mathrm{A}_{0}$ (Eq. 1) (Additional file 1: Table S5a). Similar to $\mathrm{k}_{\triangle \mathrm{E} 00}, \mathrm{~A}_{0}$ was found to be a function of $\left[\mathrm{O}_{2}\right], \mathrm{RH}$ and $\mathrm{E}_{\mathrm{v}}$ $\left(\mathrm{A}_{0}=1.34 \cdot\left[\mathrm{O}_{2}\right]+0.48 \cdot \mathrm{RH}+2.39 \times 10^{-5} \cdot \mathrm{E}_{\mathrm{v}}, \quad \mathrm{R}^{2}=0.95\right)$ (Additional file 1: Table $\mathrm{S} 5 \mathrm{~b}$ ). Therefore, $\Delta \mathrm{E}_{00}$ was obtained by substituting $\mathrm{A}_{0}$ and $\mathrm{k}_{\triangle \mathrm{E} 00}$ in Eq. 1: where $\left[\mathrm{O}_{2}\right]$ is the concentration of $\mathrm{O}_{2}$ in the environment expressed in ratio, $\mathrm{RH}$ is the relative humidity of the environment expressed in ratio, $E_{v}$ is the illuminance in $l x, t$ is the time of degradation in day.

Equation 4 shows that there may not be linearity between $\Delta \mathrm{E}_{00}$ and $\mathrm{E}_{\mathrm{v}} \cdot \mathrm{t}$. Since lux-hours $\left(\mathrm{E}_{\mathrm{v}} \cdot \mathrm{t}\right)$ is a commonly used measure to assess and control the total light exposure of objects for storage and display in museums and archives [14, 41], for the environmental management of historical paper, the strategy of controlling the arbitrary lux-hours may not be the most effective way to control the discolouration of the objects. Therefore, the use of lux-hours in practice needs to be re-examined. Equation 4 also suggests that emphasis on illuminance alone is unlikely to sufficiently contribute to a desired outcome, especially given that the illuminance level is usually low in real situations. Strategies for environmental management need to be established by taking additional environmental factors, at least $\left[\mathrm{O}_{2}\right]$ and $\mathrm{RH}$, into account.

In reality, $\left[\mathrm{O}_{2}\right], \mathrm{RH}$, and $\mathrm{E}_{\mathrm{v}}$ have specific ranges, which contributes to the complexity to directly assess their effects from the coefficients in addition to the non-linearity in the function. One of the best ways to reveal their effects on $\Delta \mathrm{E}_{00}$ is to visualise the pairwise effects through contour plots [42-44]. Figure 7a, b shows examples of how $\Delta \mathrm{E}_{00}$ changes at different combinations of $\left[\mathrm{O}_{2}\right]$ and $t$ and combinations of $E_{v}$ and $t$, respectively. In these plots, contour lines represent the same level of $\Delta \mathrm{E}_{00}$ at an interval of 0.1 unit. In Fig. 7a, $\mathrm{RH}$ and $\mathrm{E}_{\mathrm{v}}$ are fixed at 0.5 and $50 \mathrm{~lx}$ respectively,

$$
\Delta \mathrm{E}_{00}=1.34 \cdot\left[\mathrm{O}_{2}\right]+0.48 \cdot \mathrm{RH}+2.39 \times 10^{-5} \cdot \mathrm{E}_{\mathrm{v}}+\left(0.69 \cdot\left[\mathrm{O}_{2}\right]+0.41 \cdot \mathrm{RH}+8.38 \times 10^{-6} \cdot \mathrm{E}_{\mathrm{v}}\right) \cdot \ln (\mathrm{t}), \mathrm{t} \geq 0.09
$$


Lin et al. Merit Sci

(2021) 9:130

Page 11 of 14

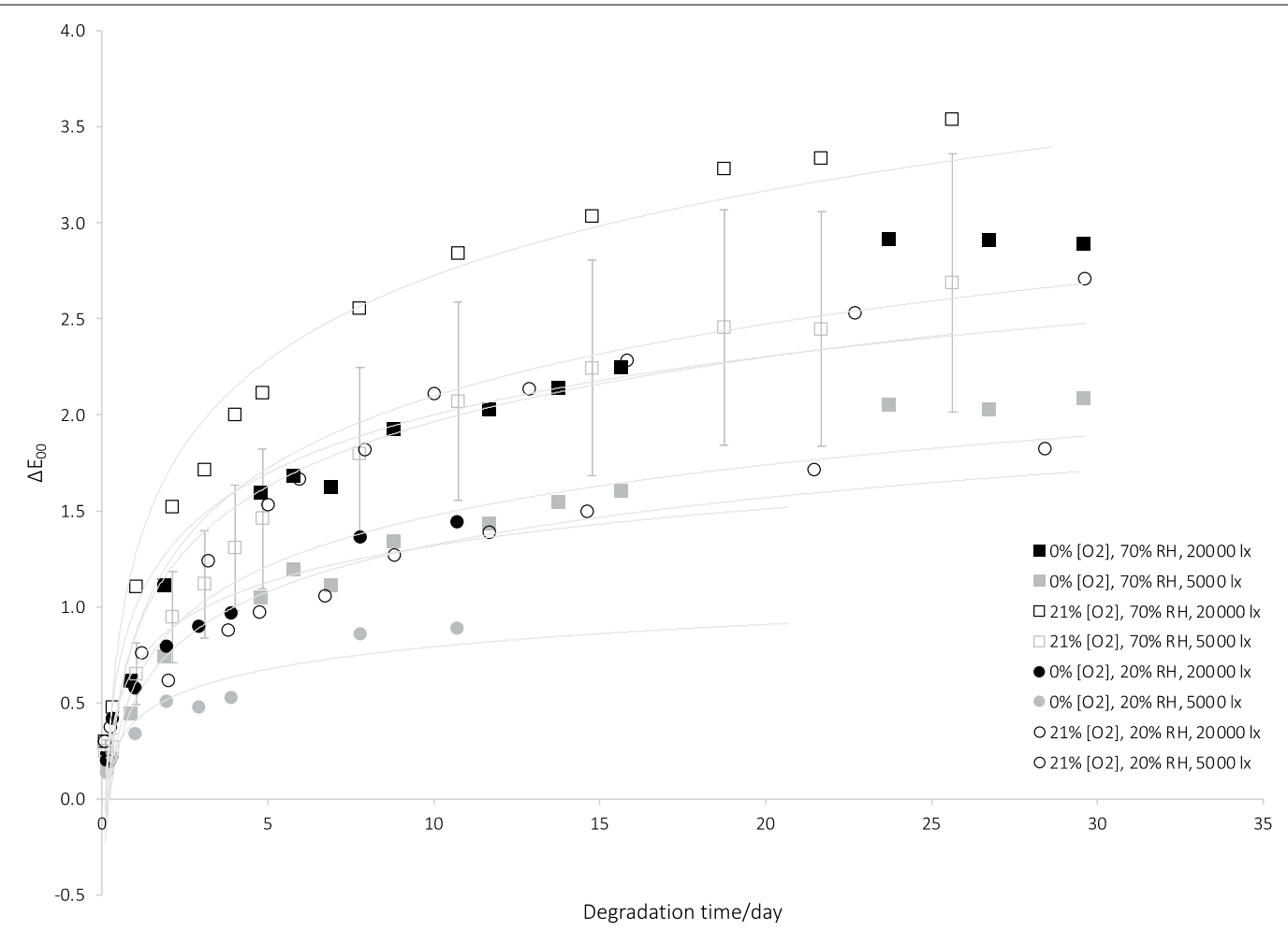

Fig. 5 Scatter plots showing the change of average $\Delta \mathrm{E}_{00}$ over time for eight experimental conditions. Trend lines indicate the logarithmic relationships, for which the coefficients and the goodness-of-fit are presented in the legend. Error bars are shown for one sample set. They represent the coefficients of variation in $\Delta \mathrm{E}_{00}$ across all the samples, which is typically $25 \%$ for all the data points

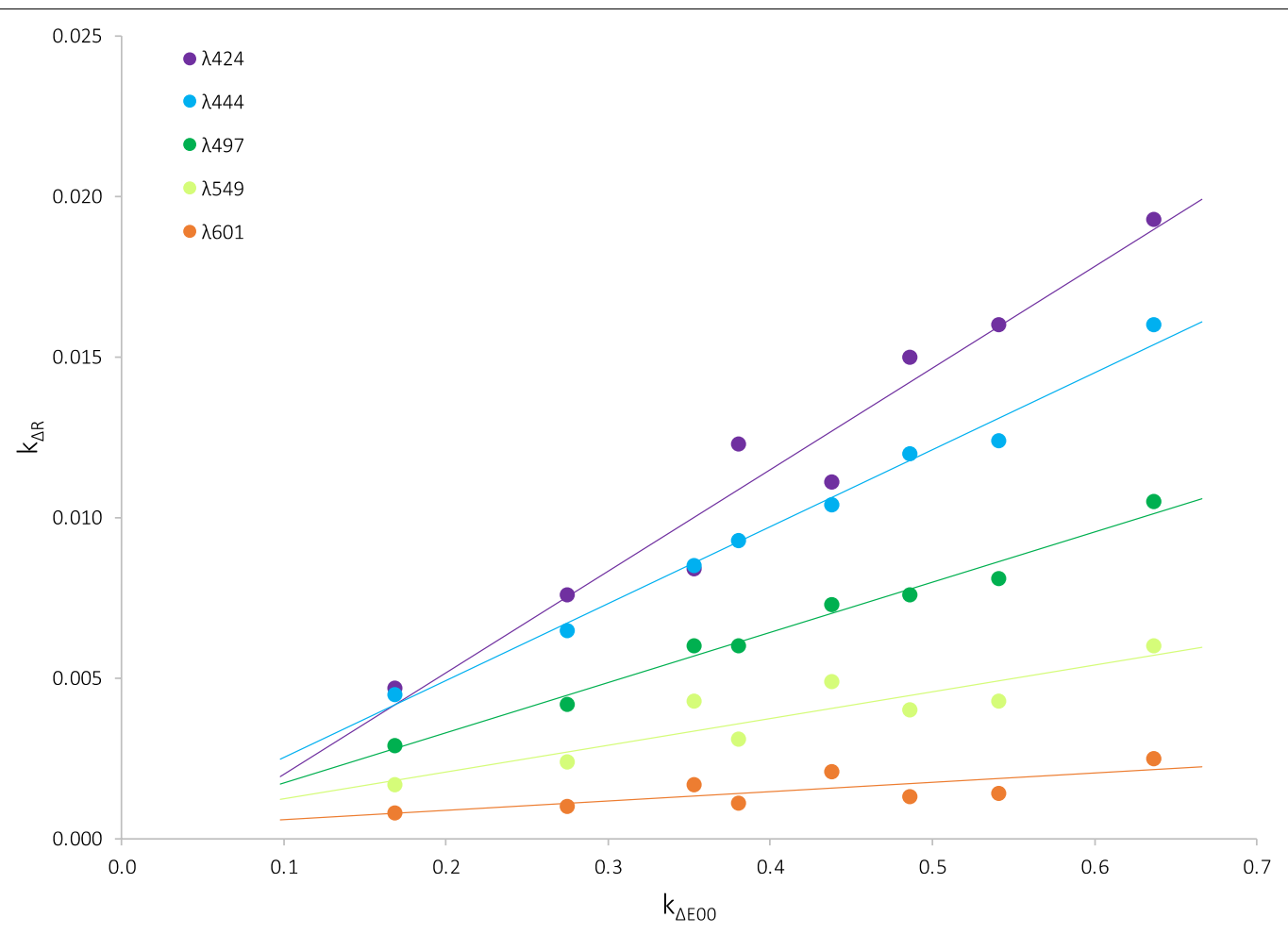

Fig. 6 The relationship between $k_{\Delta R}$ and $k_{\Delta E 00}$, which is fitted using linear models 

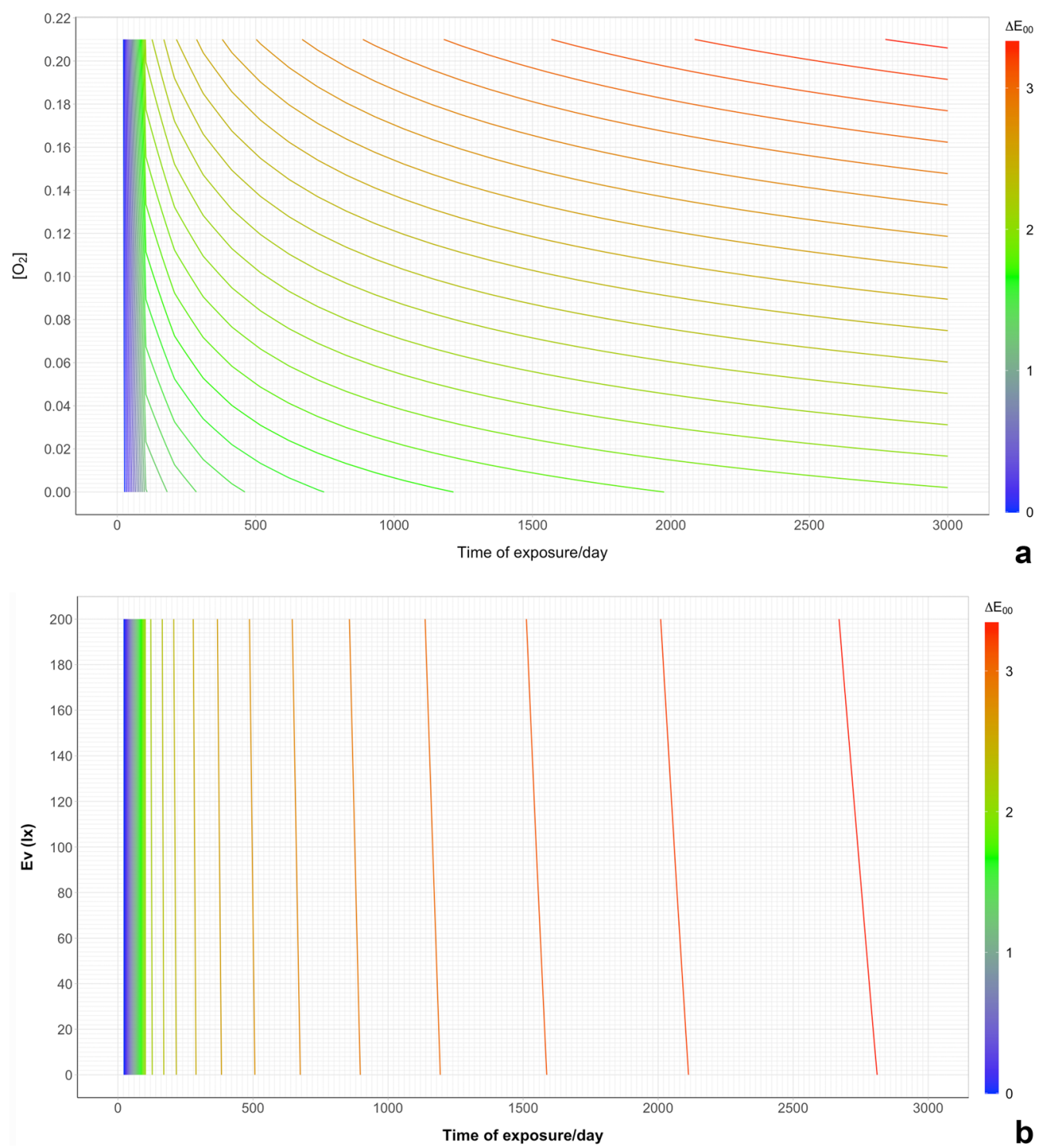

Fig. 7 a Contour plot of $\Delta \mathrm{E}_{00}$ of historical paper exploring the effects of $\left[\mathrm{O}_{2}\right]$ and $\mathrm{t}$ at $50 \% \mathrm{RH}$ and $50 \mathrm{~lx}$. $\mathbf{b}$ Contour plot of $\Delta \mathrm{E}_{00}$ of historical paper exploring the effects of $E_{v}(\mathrm{~lx})$ and $t$ at $50 \% \mathrm{RH}$ and $21 \%\left[\mathrm{O}_{2}\right]$. Each contour line represents a step of $0.1 \Delta \mathrm{E}_{00}$

representing the typical condition at exhibitions in museums. The promotion effect of $\mathrm{O}_{2}$ is clearly demonstrated in this contour plot. An anoxic environment is beneficial in slowing down the discolouration of historical paper by extending the lifetime by more than ten times. However, $\Delta \mathrm{E}_{00}$ of historical paper is likely to remain below 3 units for 3000 days of display at $50 \mathrm{~lx}$ even in an oxic environment.

\section{Conclusions and future research}

This paper discusses modelling the photodegradation of historical rag paper under polychromatic visible radiation. A $2^{3}$ full factorial experiment was designed to investigate the effects of $\left[\mathrm{O}_{2}\right], \mathrm{RH}$ and $\mathrm{E}_{\mathrm{v}}$ on the rate of degradation in spectroscopic and tristimulus colourimetric responses. Within the range of $\lambda$ investigated in the experiment (424-853 nm), measurable $\Delta \mathrm{R}$ mainly took place at $\lambda<600 \mathrm{~nm}$. Blue shifts were observed in 
$\Delta \mathrm{R}$ as degradation progressed, which provided evidence for photo-oxidation of the chromophores by oxygen radicals. Despite the complexity and uncertainties within the samples, both $\Delta \mathrm{R}$ and $\Delta \mathrm{E}_{00}$ showed strong logarithmic dependence on time. ANOVA suggested that both $\mathrm{k}_{\Delta \mathrm{R}}$ and $\mathrm{k}_{\triangle \mathrm{E} 00}$ were driven by the main effects of $\left[\mathrm{O}_{2}\right], \mathrm{RH}$ and $E_{v}$, and all three factors promoted the reactions. Within the ranges investigated, $\mathrm{RH}$ showed the strongest effect, whereas $E_{v}$ showed the weakest. Given the exaggerated experimental range of $E_{v}$, its effect in a real scenario is likely to be even smaller. Therefore, more relaxing and flexible strategies for lighting management may be adequate for the storage and display of historical rag paper. Based on the ANOVA and regression analyses, a doseresponse model for $\Delta \mathrm{E}_{00}$ was established using $\left[\mathrm{O}_{2}\right]$, $\mathrm{RH}, \mathrm{E}_{\mathrm{v}}$ and $\mathrm{t}$ as explanatory variables. In this model, the nonlinearity between $\Delta \mathrm{E}_{00}$ and $\mathrm{E}_{\mathrm{v}} \cdot \mathrm{t}$ suggested the use of lux-hour as a measure to control light exposure, thus the discolouration of historical rag paper, should be re-evaluated for effective collection management.

Within the time frame of this research, only a $2^{3}$ full factorial experiment without replications could be carried out. Although the models obtained are plausible and adequate for use in practice, performing replications in the future would lead to more accurate estimation of the errors, which would subsequently improve the estimation of the effects and their significance. In addition, the models were obtained under the assumption that the effects of factors on the response variables are linear through low to high levels. To validate the assumption and to improve the results, the current experiment can be extended to a face centred central composite design by adding two extra sets of experimental runs: a set of centre points, whose values are the medians of the values of each factor in the factorial experiment to estimate of the variance of the samples, and a set of six star points, allowing the estimation of the curvature in the correlation. Furthermore, this research mainly focused on the external causes of the spectroscopic and colour change of paper. Such an approach is of more practical value especially in supporting decision making in environmental management for collections. Although remarkably strong effects were observed without significant effects of confounding internal factors, internal causes may explain some of the observed trends and variability in the sample behaviours and provide fundamental insights into the chemical reactions in the paper-ink materials system. Therefore, with adequate time and resources in the future, monitoring the change in certain chemical and physical properties of paper would be an essential step to gain insights into the internal causes.

\section{Supplementary Information}

The online version contains supplementary material available at https://doi. org/10.1186/s40494-021-00602-4.

Additional file 1: Figure S1. Plot of the relative standard deviation (RSD) of pixels of the same paper sample over the $\lambda$ range of $424-853 \mathrm{~nm}$. Table S1. The rate constant of change in diffuse reflectance of historical paper $\left(k_{\Delta R}\right)$ at different wavelength during accelerated degradation at eight experimental conditions. $k_{\triangle R}$ is unitless. $R^{2}$ represents the goodnessof-fit of the models based on eqs. 1, 2. Table S2. (a) Summary of the coefficients for the correlation of $k_{\Delta R}$ and $\lambda$ modelled by 2 nd order polynomial curves as $k_{\Delta R}=a_{0}+a_{1} \lambda+a_{2} \lambda^{2}$ and the coefficient of determination $\left(R^{2}\right)$. (b) Summary of the regression coefficients for the correlation of $k_{\Delta R}$ and $\lambda$ modelled by $k_{\Delta R}=b_{0}+b_{1} \lambda$ and the coefficient of determination $\left(R^{2}\right)$. Table S3. Summary of $A_{0}$ and $k_{\triangle E O 0}$ for the eight experimental conditions obtained based on eqs. 1, 2. Goodness-of-fit of the models are indicated by $\mathrm{R}^{2}$. Table S4. Summary of the estimated coefficients for the regression analysis of $k_{\triangle E 0 O}$. SE represents the standard error of the estimated coefficients, t-stat and $p$ value indicate the significance of the estimated coefficients, RMSE represents the root mean square error of the fitted models, and $\mathrm{R}^{2}$ indicates the goodness-of-fit of the fitted models. Table S5. (a) Analysis of variance (ANOVA) for the effects of $\left[\mathrm{O}_{2}\right], \mathrm{RH}$, and $\mathrm{E}_{\mathrm{v}}$ on $\mathrm{A}_{0}$. (b) Summary of the estimated coefficients of the regression of $\left[\mathrm{O}_{2}\right], \mathrm{RH}, \mathrm{E}_{\mathrm{v}}$ on $A_{0}$ based on ANOVA. SE represents the standard error of the estimated coefficients, t-stat and $p$ value indicate the significance of the estimated coefficients, RMSE represents the root mean square error of the fitted models, and $R^{2}$ indicates the goodness-of-fit of the fitted models.

\section{Acknowledgements}

The authors would like to acknowledge the support by UCL Institute for Sustainable Heritage (UK), the Smithsonian's Museum Conservation Institute (USA), The National Archives (UK) and Lichtblau e.K. (Germany).

\section{Authors' contributions}

$Y L$, TF and MS jointly designed the experiment. YL carried out all the experimental runs and data analysis. All the authors discussed the results and contributed to the manuscript. All authors read and approved the final manuscript.

\section{Funding}

This research was generously supported by the Engineering and Physical Sciences Research Council (EPSRC) Centre for Doctoral Training in Science and Engineering in Arts, Heritage and Archaeology (SEAHA), UK and the Smithsonian's Museum Conservation Institute Trust Funds, USA.

Availability of data and materials

The datasets used and/or analysed during the current study are available from the corresponding author on reasonable request.

\section{Declarations}

\section{Competing interests}

The authors declare that they have no competing interests.

\section{Author details}

${ }^{1}$ Museum Support Center, Museum Conservation Institute, Smithsonian Institution, 4210 Silver Hill Rd, Suitland, MD 20746, USA. ${ }^{2}$ Department of Statistical Science, University College London, Gower Street, London WC1E 6BT, UK. ${ }^{3}$ Institute for Sustainable Heritage, University College London, Gower Street, London WC1E 6BT, UK.

Received: 13 July 2021 Accepted: 21 September 2021

Published online: 13 October 2021 


\section{References}

1. Kujirai C. Studies on the photodegradation of cellulose (IV) Infrared absorption spectra of irradiated samples (V) On the formation of cellulose peroxide. Sen I Gakkaishi. 1965;21(12):626-34.

2. Hon N-S. Formation of free radicals in photoirradiated cellulose. I. Effect of wavelength. J Polym Sci Polym Chem Ed. 1975;13:1347-61.

3. Launer HF, Wilson WK. The photochemistry of cellulose. Effects of water vapor and oxygen in the far and near ultraviolet regions. J Am Chem Soc. 1949;71(3):958-62.

4. Stillings RA, Van Nostrand RJ. The action of ultraviolet light upon cellulose. I. Irradiation effects. II. Post-irradiation effects 1. J Am Chem Soc. 1944;66(5):753-60. https://doi.org/10.1021/ja01233a029.

5. Phillips GO. Photochemistry of carbohydrates. Adv Carbohydr Chem. 1963:18:9-59.

6. Hon N-S. Formation of free radicals in photoirradiated cellulose. II. Effect of moisture. J Polym Sci Polym Chem Ed. 1975;13:955-9.

7. Hon N-S. Formation of free radicals in photoirradiated cellulose. III. Effect of photosensitizers. J Polym Sci Polym Chem Ed. 1975;13:1933-41.

8. Hon N-S. Formation of free radicals in photoirradiated cellulose. V. Effect of temperature. J Polym Sci Polym Chem Ed. 1975;13:2363-74.

9. Hon N-S. Formation of free radicals in photoirradiated cellulose. VI. Effect of lignin. J Polym Sci Polym Chem Ed. 1975;13:2641-52.

10. Hon N-S. Formation of free radicals in photoirradiated cellulose. VII. Radical decay. J Polym Sci Polym Chem Ed. 1975;13:2653-69.

11. Hon N-S. Formation of free radicals in photoirradiated cellulose. VIII. Mechanisms. J Polym Sci Polym Chem Ed. 1976;14:2497-512.

12. Hon N-S. Formation of free radicals in photoirradiated cellulose. IV. Effect of ferric ions. J Phys Conf Ser. 1975;19:2789-97.

13. Launer HF, Wilson WK. Photochemical stability of papers. J Res Natl Bur Stand. 1934;1943(30):55-74.

14. Garside D, Curran K, Korenberg C, MacDonald L, Teunissen K, Robson S. How is museum lighting selected? An insight into current practice in UK museums. J Inst Conserv. 2017;40(1):3-14. https://doi.org/10.1080/19455 224.2016.1267025.

15. Lunz M, Talgorn E, Baken J, Wagemans W, Veldman D. Can LEDs help with art conservation? - Impact of different light spectra on paint pigment degradation. Stud Conserv. 2017;62(5):294-303.

16. ASTM. Test method for accelerated light aging of printing and writing paper by xenon-arc exposure apparatus. Am Soc Test Stand. 2007;5:6789.

17. Box GEP, Hunter JS, Hunter WG. Statistics for experimenters: design, innovation, and discovery. 2nd ed. Hoboken: Wiley; 2005. p. 672.

18. Grove DM, Davis TP. Engineering, quality and experimental design. New York: Wiley; 1992.

19. Strlič M, Kolar J, editors. Aging and stabilisation paper. Ljubljana: National and University Library; 2005.

20. Sharma G, Wu W, Dalal EN. The CIEDE2000 color-difference formula: implementation notes, supplementary test data, and mathematical observations. Color Res Appl. 2005;30(1):21-30.

21. CIE. Improvement to industrial colour-difference evaluation. Vinenna: International Commission on Illumination; 2001.

22. Saunders D, Kirby J. Studies in conservation wavelength-dependent fading of artists' pigments wavelength-dependent fading of artists' pigmeNTS. Stud Conserv. 1994:39:190-4.

23. Savitzky A, Golay MJE. Smoothing and differentiation of data by simplified least squares procedures. Anal Chem. 1964;36(8):1627-39.

24. Schanda J. Colorimetry: understanding the CIE system. Hoboken: Wiley; 2007.
25. Wojciech M, Maciej T. Color difference Delta E—a survey. Mach Graph Vis. 2011;20(4):383-411.

26. Liu Y, Fearn T, Strlič M. Spectral sensitivity of the discoloration of historical rag paper. Talanta Open. 2021. https://doi.org/10.1016/j.talo.2021.100058.

27. Kirschner B, Brückle I, Henniges U. Light emitting diodes (LED) for aqueous light bleaching of paper. Restaurator. 2019;40(2):69-95

28. Zeronian $\mathrm{SH}$, Inglesby MK. Bleaching of cellulose by hydrogen peroxide. Cellulose. 1995;2:265-72.

29. Kolar J. Mechanism of autoxidative degradation of cellulose. Restaurator. 1997;18(4):163-76.

30. Hon DN-S. Photooxidative degradation of cellulose: reactions of the cellulosic free radicals with oxygen. J Polym Sci Polym Chem Ed. 1979;17(2):441-54.

31. Hurter F, Driffield VC. Photochemical investigations and a new method of determination of the sensitiveness of photographic plates. J Soc Chem Ind. 1890;9(455):76.

32. Hirt RC, Schmitt RG, Dutton WL. Solarization studies on polyester resins using a heliostat-spectrometer. Sol Energy. 1959;3(2):19-22.

33. Zerlaut GA, Ellinger ML. Precision spectral ultraviolet measurements and accelerated weathering. J Oil Colour Chem Assoc. 1981;64:387-97.

34. Daniel C. Use of half-normal plots in interpreting factorial two-level experiments. Technometrics. 1959;1(4):311-41.

35. BSI. Specification for managing environmental conditions for cultural collections PAS 198:2012. UK: BSI Standards Limited; 2012.

36. Fenech A, Dillon C, Ntanos K, Bell N, Barrett M, Strlič M. Modelling the lifetime of colour photographs in archival collections. Stud Conserv. 2013:58(2):107-16. https://doi.org/10.1179/2047058412Y.0000000081.

37. Berns RS, Alman DH, Reniff L, Snyder GD, Balonon-Rosen MR. Visual determination of industrial color-difference tolerances using probit analysis. Color Res Appl. 1991;16(5):297-316.

38. Sharma G. Digital color imaging handbook. Boca Raton: CRC Press LLC: 2003.

39. Brigham R, Grau-Bové J, Rudnicka A, Cassar M, Strlič M. Colour analysis crowdsourcing as an analytical method: metrology of smartphone measurements in heritage science. Angew Chemie Int Ed. 2018;57:7423-7.

40. Johnston-Feller R. Color science in the examination of museum objects: nondestructive procedures. Los Angeles: The Getty Conservation Institute; 2001.

41. Blades N, Lithgow K, Cannon-Brookes S, Mardaljevic J. New tools for managing daylight exposure of works of art: case study of Hambletonian, Mount Stewart, Northern Ireland. J Inst Conserv. 2017;40(1):15-33.

42. Fenech A, Strlič M, Cassar M. The past and the future of chromogenic colour photographs: lifetime modelling using near-infrared spectroscopy and enhancement using hypoxia. Appl Phys A Mater Sci Process. 2012;106(2):411-7.

43. Sebera DK. Isoperms: an environmental management tool. 1994. https:// cool.culturalheritage.org/byauth/sebera/isoperm/. Accessed 4 Oct 2021.

44. Strlič M, Grossi CM, Dillon C, Bell N, Fouseki K, Brimblecombe P, et al. Damage function for historic paper. part III: isochrones and demography of collections. Herit Sci. 2015;3(40):1-12.

\section{Publisher's Note}

Springer Nature remains neutral with regard to jurisdictional claims in published maps and institutional affiliations. 